\title{
What Should Faculty Advisors Know Before Advising Students Applying to Psychiatry Residency
}

\author{
Lia A. Thomas ${ }^{1}$ (D) $\cdot$ Dawnelle Schatte $^{2} \cdot$ Gregory Briscoe $^{3} \cdot$ Susan Lehmann ${ }^{4} \cdot$ Shriti B. Patel $^{3}$ \\ Received: 31 August 2020 / Accepted: 15 March 2021 / Published online: 25 March 2021 \\ (C) This is a U.S. government work and not under copyright protection in the U.S.; foreign copyright protection may apply 2021
}

The process of applying to residency is fraught with opportunity and anxiety. Medical students make many decisions in a short time frame and often rely on faculty to help them navigate this process. The faculty advisor - a role with no clear job description - can be critical to the success of students making the transition from medical school to residency, and preparation for this role varies by school and individuals.

We identify the following areas to be crucial in the role of faculty advisor, and thus for faculty to be prepared to advise on: the process of applying, letters of recommendations, personal statements, and interview preparation. This column will also discuss some of the ethical issues that may arise when serving as faculty advisor. Where possible, we will also direct the readers to articles and additional resources.

\section{Overarching Guidance}

There is no one defined way to structure faculty advising. Among the authors of this paper, one had a group of identified psychiatric educators serving as faculty advisors, one institution assigned fourth year medical students to identified faculty regardless of specialty match, and others had no formal structure. Given this variety, the authors wish to stress that faculty advisors need do not need to know all the answers nor should they work in isolation. Staying abreast of contemporary issues affecting students applying in their current, match cycle is important and reviewing listservs and websites of the many academic psychiatric organizations can provide some

Lia A. Thomas

Lia.Thomas@UTSouthwestern.edu

1 UT Southwestern Medical Center, Dallas, TX, USA

2 University of Texas Medical Branch, Galveston, TX, USA

3 Eastern Virginia Medical School, Norfolk, VA, USA

4 Johns Hopkins University School of Medicine, Baltimore, MD, USA guidance. In 2020, issues related to the COVID-19 pandemic dramatically changed the landscape of psychiatry residency applicant interviews across the nation. Interviews were virtual, away rotations canceled, and key examinations were paused or suspended [1]. Knowledge about what is happening and how to help your trainee navigate these changes is crucial.

In recent years, these organizations created a living document called "A Roadmap to Psychiatric Residency" [2]. This can serve as a guide in helping both faculty advisor and student in making decisions and developing a timeline of their process. Faculty advisors should utilize resources at the local institution - the Deans of Students Affairs/Academic Affairs Offices may also provide overview guidance. If there are several persons serving as faculty advisors at a single institution, consider meeting during the interview season to exchange knowledge and brainstorm challenges. We recommend creating an identified list of faculty advisors that can be easily accessed by students.

We recommend starting the advising process by getting to know the individual medical student. Learning about their lives, their reasons for choosing to match into psychiatry, and sharing a bit of yourself can make this relationship successful.

\section{Advising on the Process of Applying-How to Choose Programs and Number of Programs to Apply to}

The number of programs a student applies to depends on the strength of the student's academic achievements, and advisors should recommend students consider applying to some "safety schools" that are not out of reach given their qualifications (grades, Step 1 Score, quality of MSPE comments, other noteworthy characteristics). The National Resident Matching Program (NRMP) regularly publishes "Charting Outcomes in the Match" by U.S. Allopathic, U.S. Osteopathic, and foreign medical graduates [3]. Advisors can guide students to review how competitive they would have been using the 
published previous year's data based on scores, publications, and experiences (research, work, and volunteer). Although the number of applicants to psychiatry residency continues to grow in recent years, faculty can assuage students' anxieties by reviewing the "Charting Outcomes in the Match." For example, $90 \%$ of applicants who ranked nine programs matched in 2020. In general, students do not need to have their Step 2 Score posted at the time of application, but students who think they underperformed on Step 1 may wish to take Step 2 sooner rather than later so that it is available to Program Directors when they first review the application.

Advisors should stay informed about what program directors are looking for in an application. Advisors may want to communicate directly with the Program Director at their institution or nearby programs to gather this information. They may also want to touch back with students after they have matched to develop a mental list of what students from their own institution report about programs, as well as where they matched. In this way, advisors gain a broader view of the current recruitment landscape for future advising.

When advising students about which programs to apply to, we recommend faculty ask students to identify what they are looking for in a program. Students may prioritize geographical proximity to family or wanting to live and experience a different area of the country. Students may desire programs that offer post-residency fellowship training, programs that help residents develop along special tracks (research, educational, community or rural psychiatry, etc.), programs that promote diversity, or programs of a particular size. The Association of American Medical Colleges (AAMC) Careers in Medicine website has specialty-specific resources for each residency to help students make selections in the Residency Programs section [4].

\section{Letters of Recommendations}

The well-informed faculty advisor should be aware that letters of recommendation (LORs) are particularly "high stakes" for students completing residency applications [5]. Advisors should convey to students that the LOR communicates the essence of an applicant as observed in real-world experience and speculation regarding future resident performance. Advisors should inform students that the LOR is often weighed as heavily as grades or other evidence of academic merit, and that its importance has been validated in a limited number of studies [6,7].

Faculty advisors should ask applicants to reflect on who would know them best and be able to discuss their relevant qualities in detail [8]. Students may be surprised to learn that training directors generally place more value on a highly enthusiastic letter from a faculty member who knows the applicant well as opposed to a more generic letter from a nationally renowned faculty member less familiar with the applicant's work [9]. Advisors should relay to applicants that, once potential letter writers are chosen, the student should ask each for a "strong letter of recommendation" and create an opportunity for this person "to accept (delightedly) or to decline (gracefully)" [5]. If the response of the candidate letter writer is clearly ambiguous, the student should pay special attention to its tone. A halfhearted response may serve as a harbinger of a forthcoming mediocre LOR, and the student may wish to retract the request. Advisors may wish to alert applicants that they must be prepared to provide an appropriate and organized set of materials to the letter writer, e.g., a curriculum vitae (CV), recent publications, list of other activities or accomplishments, and that a personal statement may also be helpful [5].

Advisors may be asked by students about the waiver of their legal right to review their LORs. Students should be informed that "residencies generally prefer letters that include the notation that the subject has waived that right, presumably allowing a more candid reflection in the letter of the writer's true opinions" [10].

Advisors should be aware that the NRMP limits the number of LORs one can submit to four. If the applicant has more than four available letters, he or she may wish to discuss which ones to select for submission. Advisors should ready themselves for questions such as "How important is a letter from a nonpsychiatric attending (in another medical specialty)?" "If I don't use the letter from the psychiatric attending on my core psychiatry clerkship, will this raise questions since the core is so important?" "Do I need to have a letter from my research PI, with whom I spent a year?," etc. There is scant literature which directly addresses these questions, yet students may wish to review a 2016 NRMP Program Director survey (all specialties and specialty specific) in which the mean importance rating of "Letters of recommendation in the specialty" was 4.2 out of five [11]. However, among the 39 rated elements, the importance rating of LOR outside the specialty was not listed. The student and faculty advisor are left to draw their own conclusions.

\section{Guidance on Personal Statements}

The 2020 NRMP Residency Program Director Survey showed $86 \%$ of psychiatry programs cited the personal statement as a factor in interview selection [11]. This data suggests that the content of the personal statement is valuable in early review of applications. Personal statements provide the student an opportunity to highlight strengths and characteristics, while preemptively addressing areas of concern. Some students may only request grammatical editing, while others may request feedback on the content of their statement. General editing from an advisor may include a review of the essay's readability, structured organization, accurate use of language, clarity of thought, and how this might be perceived by a potential program committee. 
Students often question what type of information residency committees are looking for. The faculty advisor is in a unique position to help students reflect on individual qualities and meaningful experiences that could be shared in order to express a sincere interest in pursuing psychiatry. Advisors can better engage the student by using a curious rather than directive approach, similar to the style by which psychiatrists interview patients. It may be helpful to have the student reflect on challenging concepts, such as an issue in psychiatry that excites the student, advancements in the field they would like to see, or distinctive qualities the student possesses that would help contribute to a successful career involving patient care, research, and/or academics [12]. Consider asking the student to explore concepts that may not be obvious in the curriculum vitae. For example, is it important for the student to share career goals, along with the type of training the student envisions to meet those goals? Is it valuable for this student to highlight unique attributes and experiences that may not be gleaned through the rest of the application? Might the student who values inclusiveness in residency utilizes this essay to celebrate personal attributes, such as their ethnicity or sexual minority status? Perhaps there is a gap in training that could be addressed, or a nontraditional path that should be highlighted and has fostered growth or resilience. The faculty advisor may recognize and help the student clarify areas of an application that generally raise concern from an applicant committee.

The faculty advisor may be approached on how a student should address sensitive subjects, such as personal or medical challenges. Applicants may struggle with the decision to share personal information, such as past substance impairment or psychiatric history. Guidance should be given that confidentiality of essay content may not be guaranteed, given the variable nature of applicant committees [13]. A randomized survey of program directors from residencies accredited by the Accreditation Council for Graduate Medical Education (ACGME) indicated that self-disclosure of mental illness, such as depression, may lower the chance of an applicant obtaining an interview, indicating continued bias against disclosure [14]. However, it was noted that the personal statement is the place for thoughtfully disclosing an illness if there is a purpose for sharing. An applicant may recognize an illness or painful experience as an element of personal growth or a source of empathy. Since there is potential for any content in the personal statement to be addressed in the interview setting, the faculty advisor can help the student assess a willingness to discuss and expand on personal topics. The faculty guide can help the student process the potential outcomes of sharing sensitive information in the personal statement.

\section{Interview Preparation}

Another key aspect of advising is helping student prepare for residency interviews. Advisors should urge students to become familiar with basic information available on a program's website prior to interviewing and be prepared to talk about their specific interest in that program. Students should expect to elaborate on anything shared in their personal statement and CV and should be prepared to discuss any aberrations on their transcript or any unusual circumstances they have dealt with that impacted their education trajectory. They may not consider that interviewers may ask them about their post-residency career plans. This question may come up at programs that provide tracks in various disciplinary areas, such as research or education, and are looking to see which applicants may best fit those tracks or future career directions. While students should be reassured that they are not required to make any commitments, it is helpful for them to give this question some thought in advance. Most students will benefit from role-play and practice interviews to help them gain confidence in sharing their story and in answering open-ended and commonly asked questions.

In 2020, residency interviewing occurred virtually, due to the COVID-19 pandemic and was endorsed by the AAMC and ACGME $[1,15]$. In the coming year, it is unknown to what extent virtual interviewing will continue, and advisors need to be prepared to guide students for this possibility. The elimination of the time and significant expenses associated with travel to residency sites as a result of virtual interviewing will be considered a boon to most medical students. At the same time, there may be new concerns - students may worry about how they will come across during a virtual interview and whether their social skills and personal warmth will come through. Students may be concerned about talking too fast, or about time lags in virtual platforms that can create halting conversation. They may also worry how an interviewer will react if a housemate inadvertently is seen on the screen. Faculty advisors should talk with their advisees about these concerns and reassure them that interviewers appreciate the limitations and challenges that virtual interviews present.

It may be helpful for faculty advisors to provide students with a checklist to be sure that they have the equipment and environment needed to have successful virtual interviews. Students should be intentional about their backgrounds and should test out the lighting and internet connectivity. Students should be advised to close all other open programs, including email, to prevent additional sounds. They should be reminded to dress professionally for each interview, just as they would for an in-person interview and to be on-time for scheduled interviews. Another important point is telling students to practice looking at the person on the screen to "make eye contact" with the interviewer, and not to look at their own image on the screen [16]. Encourage your student advisees to familiarize themselves with commonly used platforms and to consider mock virtual interviews.

With virtual interviews, it may also be more difficult for students to get a good sense of the culture and environment of 
the training program in order to gauge whether a given program will be a good "fit." In addition to posting podcasts or videos for applicants on the program's website, residency programs may set up optional virtual "social hours" with current residents and applicants to give candidates the opportunity to talk more freely with them about their experiences and the ethos of the residency program. Medical students should be encouraged to take advantage of these more informal opportunities to learn more about what the residents see as the strengths of the program, as well as areas for improvement.

In addition to the pandemic of 2020, US medical students, and the USA as a whole, came to a reckoning on racism in America with the deaths of George Floyd, Breana Taylor, and Ahmed Aubrey. In early 2021, the American Psychiatric Association (APA) issued a formal apology on its role in structural racism [17]. Students may want guidance on how to ask how programs are addressing diversity, equity, inclusion, and anti-racism issues in their residency programs.

\section{Ethical Issues for Faculty Advisors}

How much "help" do you provide an applicant? Remember that applicants will need to stand on their own before their interviewers. Your role is to provide guidance, and to be a fair and accurate advocate. Provide your advice on their personal statement, but do not re-write it for them. Similarly, do not encourage your advisees to embellish an experience or add something to their $\mathrm{CV}$ that they did not do. There is a growing body of literature speaking to "phantom publications," with an observation that 6-9\% of applicants had unverifiable publications listed on their CV $[18,19]$.

What is your role during interview season? Whether to write letters to program directors on behalf of the applicant is a complicated question. Before you write any letters, make sure that your student is advocating for themselves and has already reached out to programs, and then ask yourself what is the goal of you writing a letter?

A corollary of this is to be honest with your applicants. If your advisee is not meeting expectations, or if they are not a competitive candidate, inform them of this. Work with them on preparing to apply for a second residency, increasing the number of applications, or having to enter the Supplemental Offer and Acceptance Program (SOAP). While there may be initial disappointment from the advisee, the feeling of being misled and/or not matching at all is significantly more damaging.

If you are a faculty advisor who also serves in your residency program's leadership, take a moment to reflect on these roles. As a program director, you are looking for the best candidates for your program. As a faculty advisor, you are helping a student find the best place for their residency. Sometimes these two spheres overlap; sometimes they do not. Be clear with yourself and your advisees. Remember that all parties are bound by the rules and regulations of the NRMP. As mentioned earlier in this paper-if you are a program director in a department that has the resources - consider creating a committee of faculty advisors so that more persons can share the work of faculty advising. At one author's institution, students are aware that while their faculty advisors may be part of the residency leadership, all serious conversations about potential matching at their home institution are handled by the program director. Other considerations are to have the program director be separate from all faculty advising discussions; these arrangements will be determined by the number of psychiatric educators available at your institution.

\section{Final Statement: Serving as a Faculty Advisor}

Faculty advisors have an important role in helping students put their best selves forward in the application process. This can be especially critical for students who do not have resources to pay for private advisors or families with physician members. As a crucial student advocate, the faculty advisor can help students consider choices, make use of available resources, and feel confident about their decisions.

\section{Declarations}

Ethical Considerations N/A

Disclosure On behalf of all authors, the corresponding author notes that there is no conflict of interest.

\section{References}

1. American Association of Medical Colleges. Washington, DC [date unknown]. American Association of Medical Colleges (AAMC) coronavirus hub; 2020. Available from https://www.aamc.org/ coronavirus-covid-19-resource-hub. Accessed 1 Aug 2020

2. American Psychiatric Association. Washington, DC [date unknown]. A roadmap to psychiatric residency; 2019; Available from: https://www.psychiatry.org/residents-medical-students/medicalstudents/apply-for-psychiatric-residency. Accessed 1 Aug 2020

3. National Residency Matching Program (NRMP). Washington, DC [date unknown]. Main residency match data and reports; 2020; Available from https://www.nrmp.org/main-residency-matchdata/. Accessed 2 Aug 2020

4. American Association of Medical Colleges. Washington, DC [date unknown]. AAMC careers in medicine c2020. Available from: https://www.aamc.org/cim/. Accessed 2 Aug 2020

5. Roberts LW, Termuehlen G. (Honest) Letters of recommendation. Acad Psychiatry. 2013;37(1):55-9.

6. Appleby DC/Association for Psychological Science. [location and date unknown]. A developmental strategy to write effective letters of recommendation; 2005. Available from: https://www. 
psychologicalscience.org/observer/a-developmental-strategy-towrite-effective-letters-of-recommendation. Accessed 15 Aug 2020

7. Chang AK, Morreale M, Balon R. Factors Influencing Psychiatry Residency Applicant Selection for Interview. Acad Psychiatry. 2017;41(3):438-9.

8. Bak MK, Louie AK, Tong LD, Coverdale J, Weiss RL. Applying to psychiatry residency programs. Acad Psychiatry. 2006;30(3):23947.

9. Varley CK, Kaye D, Cowley D, Schwartz M, Forstein M, Sexson S, et al. Guidelines for the general psychiatry application process and for inter-residency transitions. Acad Psychiatry. 2012;36(6):43642.

10. Roberts LW. Academic Medicine Handbook- a guide to achievement and fulfillment for academic faculty. 2nd ed. Switzerland AG: Springer Nature; 2020. p. 138.

11. National Residency Matching Program (NRMP). Washington, DC. [date unknown]. Results of the 2020 NRMP program director survey; 2020; Available from https://mk0nrmp3oyqui6wqfm. kinstacdn.com/wp-content/uploads/2020/08/2020-PD-Survey.pdf. Accessed 21 Feb 2021

12. Woo R, Krawczyk Oman JA, Byrn L, Wakim NM, Dyne PL, Cheaito MA, et al. Writing the curriculum vitae and personal statement. J Emerg Med. 2019;57(3):411-4.

13. Chandran L, Chandran AS, Fischel JE. Crafting compelling personal statements. Acad Psychiatry. 2020;44(6):785-8.

14. Pheister M, Peters RM, Wrzosek MI. The impact of mental illness disclosure in applying for residency. Acad Psychiatry. 2020;44(5): 554-61.

15. Accreditation Council for Graduate Medical Education (ACGME). Chicago, IL [date unknown]. Recommendations for away rotations and interviews for graduate medical education fellowship applicants during the 2020-2021 academic year; 2020. Available from: https://acgme.org/Newsroom/Newsroom-Details/ArticleID/10421/ Recommendations-for-Away-Rotations-and-Interviews-forFellowship-Applicants-in-2020-2021. Accessed 10 Feb 2021

16. American Association of Medical Colleges. Washington, DC. [date unknown]. American Association of Medical Colleges (AAMC) Final report and recommendations for medical education institutions of LCME-accredited, U.S. osteopathic, and non-U.S. medical school applicants; 2020. Available from: https://www.aamc.org/ system/files/2020-05/covid19 Final Recommendations Executive Summary Final 05112020.pdf. Accessed 1 Aug 2020

17. American Psychiatric Association. Washington, DC. [date unknown]. American Psychiatric Association. APA's apology to Black, indigenous and people of color for its support of structural racism in psychiatry. 2021. Available from: https://www. psychiatry.org/newsroom/apa-apology-for-its-support-ofstructural-racism-in-psychiatry. Accessed 24 Jan 2021

18. Caplan JP, Borus JF, Chang G, Greenberg WE. Poor intentions or poor attention: misrepresentation by applicants to psychiatry residency. Acad Psychiatry. 2008;32(3):225-9.

19. Tamez HM, Tauscher R, Brown EN, Wayman L, Mawn LA. Rate of unverifiable publications among ophthalmology residency applicants invited to interview. JAMA Ophthalmol. 2018;136(6):630-5.

Publisher's Note Springer Nature remains neutral with regard to jurisdictional claims in published maps and institutional affiliations. 